\title{
Acetic Acid Acting as a Signal Molecule in Quorum Sensing System Enhances Production of 2,3- Butanediol in Saccharomyces Cerevisiae
}

\section{Chi Zhang}

Heilongjiang University

Tianqi Tong

Heilongjiang University

Jingping Ge ( $\sim$ gejingping@126.com )

Heilongjiang University https://orcid.org/0000-0003-1194-4325

\section{Research Article}

Keywords: Signal molecule, Quorum sensing, Acetic acid, 2,3-butanediol, Saccharomyces cerevisiae, Acetobacter pasteurianus

Posted Date: February 25th, 2021

DOI: https://doi.org/10.21203/rs.3.rs-238949/v1

License: (c) (i) This work is licensed under a Creative Commons Attribution 4.0 International License. Read Full License 
1 Acetic acid acting as a signal molecule in quorum sensing system enhances production of 2,3-

2 butanediol in Saccharomyces cerevisiae

3 Chi Zhang ${ }^{1,2} \quad$ Tianqi Tong ${ }^{1,2} \quad$ Jingping $\mathrm{Ge}^{1,2, *}$

$4{ }^{1}$ Engineering Research Center of Agricultural Microbiology Technology, Ministry of Education,

$5 \quad$ Heilongjiang University, Harbin 150500, China

$6{ }^{2}$ Key Laboratory of Microbiology, College of Heilongjiang Province, School of Life Sciences,

7 Heilongjiang University, Harbin 150080, China

8 *Author for correspondence: Phone number: +86-0451-86609106; Fax: +86-0451-86608046; Email

9 address: gejingping@126.com

10 


\section{Abstract:}

Objectives: 2,3-butanediol (2,3-BD) has been extensively used in chemical synthese. The traditional 2,3BD production method has low yield and high cost. This study aimed to explore the use of acetic acid as a signal molecule to initiate a quorum sensing $(\mathrm{QS})$ system in order to promote the production of 2,3-BD in Saccharomyces cerevisiae W141.

Results: We found that the yield of 2,3-BD from S. cerevisiae W141 is proportional to the cell density. S. cerevisiae W141 does not produce 2,3-BD when cell density was lower than the threshold concentration $\left(O D_{600 \mathrm{~nm}}=10\right.$ or cell density $\left.4.4 \times 10^{8} \mathrm{CFU} / \mathrm{mL}\right)$. When $1.5 \mathrm{~g} / \mathrm{L}$ acetic acid was added in the fermentation process, the yield of 2,3-BD was the highest reaching $3.01 \pm 0.04 \mathrm{~g} / \mathrm{L}(84 \mathrm{~h})$. Subsequently, we found that S. cerevisiae W141 was co-cultured with Acetobacter pasteurianus Huniang 1.01 under the optimal conditions and the acetic acid production was increased by $76.7 \%$ and $30.6 \%$ compared with the original strain and the strain with $1.5 \mathrm{~g} / \mathrm{L}$ acetic acid, respectively. In addition, the yield of 2,3-BD was respectively increased by $81.9 \%$ and $3.3 \%$. The above results are attributable to the increased activity of acetolactate synthase (ILV2) and 2,3-BD dehydrogenase (BDH1) and the increase of the relative expression of $i l v 2$ and $b d h 1$ genes.

Conclusion: Our data showed that biosynthesis of 2,3-BD was regulated by acetic acid as a signaling molecule. Moreover the study provides a deeper understanding of the mechanisms underlying between acetic acid and 2,3-BD production.

Keywords: Signal molecule; Quorum sensing; Acetic acid; 2,3-butanediol; Saccharomyces cerevisiae; Acetobacter pasteurianus 


\section{Introduction:}

The signal molecules are metabolites of bacterial growth, which can mediate quorum sensing (QS) system. The concentration of the signal molecules in the environment is directly proportional to the density of bacteria (Zhou et al. 2019). When the concentration reaches the threshold concentration, signal molecules will drive or inhibit the expression of biological characteristics genes in bacteria to regulate population behavior, further improving the ecological relationship of the population to adapt to environmental changes (Studer et al. 2008; Kareb and Aïder 2019). Finally, it realizes physiological functions and regulatory mechanisms that cannot be accomplished by a single cell (Sun et al. 2016; Arena et al. 2017). When the signal molecules interact with the QS system, in addition to the information exchange between the cells, increasing attention has been paid to intracellular metabolism and cell growth state (Jia et al. 2018; Parente et al. 2010). Since the QS system can use the signal molecules as media to regulate the ecological relationship of different microorganisms to change the physiological state of microorganisms, QS system provides high research significance in bacteria. At the same time, large quantities of signal molecules have been identified, such as acetate and oligopeptides (Studer et al. 2008; Camilli and Bassler 2006).

At present, the gradual depletion of petroleum has reawakened people's strong interest in the production of bio-based chemicals including 2,3-butanediol (2,3-BD) from biofuels (Cho et al. 2012; Ge et al. 2020). However, 2,3-BD was originally separated from nature. Its yield is low and cannot be used in industrial production. Therefore, therefore the current research concentrates on seeking a new strain and using metabolic engineering methods to increase the yield of 2,3-BD. In recent years, the production of 2,3BD by microbial fermentation has become the focus of attention both at home and abroad (Celińska and Grajek 2009). The advantage of the proposed method is that it cannot only efficiently use glucose and other monosaccharides as carbon sources, but also use plant straws as raw materials to ferment to produce 2,3-BD. The method is cheap and safe (Gao et al. 2019; Kim et al. 2016; Kim et al. 2015). Although numerous microorganisms have been studied for the production of 2,3-BD, however Saccharomyces cerevisiae has become the main platform microorganism for many related researches due to its compliance with the principle of safe production (Turner et al. 2016). Although S. cerevisiae can naturally produce $2,3-\mathrm{BD}$, yet $S$. cerevisiae uses glucose to produce 2,3-BD by fermentation, which is usually accompanied by the formation of various metabolites and by-products (Fig. 1), such as ethanol and glycerol, competing for carbon sources in metabolic pathways. Ultimately, the lower yields of 2,3- 
BD can be generated.

In the early stage of the current project, molecular biology was used to modify the metabolic pathway of S. cerevisiae, aiming to increase the yields of 2,3-BD. The results demonstrated that although the yield of 2,3-BD was improved in a short time, but the yield of 2,3-BD presented a slight downward trend due to defects such as poor genetic stability of the engineered strain. Consequently, in order to solve the present problem, this research attempts to depend on ecological principles and make attempts to enhance the ecological relationship of strains from the perspective of QS to increase the yield of 2,3-BD. Studies have demonstrated that for microorganisms, alkaline conditions are conducive to the formation of acids, and acidic conditions contribute to the formation of alcohols (Guo et al. 2017; Priya et al. 2016). Similarly, acetic acid can effectively activate the gene expression of pyruvate to 2,3-BD under low $\mathrm{pH}$ conditions and promote the synthesis of 2,3-BD. Meanwhile, acetic acid serving as a fermentation product can provide a powerful weapon for cell population competition and make microorganisms profit in ecological competition. At the same time, acetic acid can also be used as a backup carbon source to regulate the population behavior of cells (Anane et al. 2017). Therefore, in the metabolic process, the production of 2,3-BD may be regulated by QS, and acetic acid as a signal molecule can initiate QS system in order to increase the production of 2,3-BD. In other words, it is beneficial to the production of 2,3-BD under acidic conditions. Therefore acetic acid exerts an indispensable role in the 2,3-BD production process. Meanwhile, the Acetobacter pasteurianus Huniang 1.01 in the present study can produce acetic acid because the cells contain a large amount of alcohol dehydrogenase $(\mathrm{ADH})$, aldehyde dehydrogenase (ALDH) and the coenzyme pyrroloquinoline benzoquinone (PQQ). Alcohol is oxidized to aldehyde under the combined action of $\mathrm{ADH}$ and $\mathrm{PQQ}$, and aldehyde is further oxidized to acid under the action of ALDH and PQQ (Fig. 1) (Mamlouk and Gullo 2013). We co-culture S. cerevisiae W141 and A. pasteurianus $\mathrm{HN} 1.01$ to explore the drive of acetic acid on QS under co-cultivation mode, further explore the mechanism of acetic acid as a signal molecule, and clarify the relationship between the signal molecule and 2,3-BD in the QS system. Simultaneously, it provides a theoretical basis for the production of 2,3-BD by S. cerevisiae.

\section{Materials and Methods:}

\section{Bacterial strains and growth conditions}


The strains used were S. cerevisiae W141 and A. pasteurianus HN 1.01 in this study. Both bacterial strains were maintained in the Key Laboratory of Microbiology, Heilongjiang University, China.

S. cerevisiae W141 was grown at $30{ }^{\circ} \mathrm{C}$ in Yeast Extract Peptone Dextrose (YEPD) liquid medium (2\% peptone, $1 \%$ yeast extract, and $2 \%$ glucose; w/v). The initial $\mathrm{pH}$ was adjusted to 7.0 . The loading volume was $125 \mathrm{~mL} / 250 \mathrm{~mL}$. Flask cultures were maintained at $140 \mathrm{rpm}$ for 12-18 h. A. pasteurianus $\mathrm{HN} 1.01$ was grown in seed medium containing $0.2 \%$ peptone, $1 \%$ yeast extract, $9 \%$ glucose, $0.1 \% \mathrm{KH}_{2} \mathrm{PO}_{4}, 0.02 \%$ $\mathrm{MgSO}_{4} \cdot 7 \mathrm{H}_{2} \mathrm{O}$, and $4 \%$ ethanol in $1 \mathrm{~L} \mathrm{H}_{2} \mathrm{O}$. This was incubated at $37^{\circ} \mathrm{C}$ for $12-18 \mathrm{~h}$ at a shaking speed of $150 \mathrm{rpm}$ to grow the population.

\section{Cell threshold concentration of $S$. cerevisiae W141}

Overnight bacterial cultures of $S$. cerevisiae W141 that were grown in YEPD liquid medium for 12-18 h at $30{ }^{\circ} \mathrm{C}$ at a shaking speed of $140 \mathrm{rpm}$ and were centrifuged (two times at $4500 \mathrm{r} / \mathrm{min}$ for $15 \mathrm{~min}$ ) to recover the cells. The harvested cells were washed with sterile $0.9 \%$ saline. 9 different culture conditions were set to control cell density by adjusting the amount of carbon source in medium $(100 \%, 50 \%, 20 \%$ carbon source) and inoculation amount $(0.5 \%, 2 \%, 5 \%)$ and incubated for $96 \mathrm{~h}$ at $30^{\circ} \mathrm{C}$ at a shaking speed of $140 \mathrm{rpm}$. The cell density $\left(O D_{600 \mathrm{~nm}}\right.$ value $)$ and the yield of 2,3-BD in different culture conditions were determined by spectrophotometry and high performance liquid chromatography (HPLC). Accordingly, in order to determine the minimum inhibitory threshold concentration, and the minimum cell density in the medium that would not inhibit microbes.

\section{Effects of different concentrations of acetic acid on 2,3-BD}

Firstly, S. cerevisiae W141 strains were precultured. Subsequently, S. cerevisiae W141 were inoculated into $150 \mathrm{~mL} / 500 \mathrm{~mL}$ YEPD liquid medium at 5\% inoculation volume. Inoculation volume of acetic acid were set to $1 \mathrm{~g} / \mathrm{L}, 1.5 \mathrm{~g} / \mathrm{L}$ and $2 \mathrm{~g} / \mathrm{L}$ for $96 \mathrm{~h}$ at $30{ }^{\circ} \mathrm{C}$ at a shaking speed of $140 \mathrm{rpm}$. The original strain S. cerevisiae W141 was used as the control group. The changes in cell density (OD $600 n m$ value) and 2,3BD concentration were detected by spectrophotometry and HPLC. The effects of different acetic acid concentrations on 2,3-BD were observed. Thus, the optimal concentration of acetic acid can be determined to ensure the highest yield of 2,3-BD.

\section{Orthogonal optimization experiment}


and inoculation time are further optimized. This study uses four-factor $\mathrm{L}_{9}\left(3^{4}\right)$ orthogonal design, each factor has three different levels (Table 1).

\section{Establishment of co-culture system and index detection}

The strains were individually precultured as described above. The strains S. cerevisiae W141 and A. pasteurianus HN 1.01, which were used in the co-culture experiment, were inoculated in their respective liquid medium and grew to the logarithm phase. Then these cultures were inoculated into fresh broth for continuous culture for $96 \mathrm{~h}$ at $30{ }^{\circ} \mathrm{C}$ at a shaking speed of $140 \mathrm{rpm}$. According to the physiological characteristics of S. cerevisiae and A. pasteurianus, the results of orthogonal optimization test were used as the optimal conditions for co-culture fermentation. Spectrophotometry and HPLC were used as detection methods, the yield of 2,3-BD and acetic acid was used as the detection standard, samples were taken every $12 \mathrm{~h}$, single culture treatment of each strain was used as the control group. The cell density $\left(O D_{600 n m}\right.$ value) was determined by spectrophotometry. The content of 2,3-BD, acetic acid, glucose and ethanol were determined by HPLC.

\section{Real-time quantitative polymerase chain reaction to measure ilv2 and $b d h 1$}

RNA was extracted from samples by using the RNA Prep Pure Bacteria Kit (Tiangen Biotech Co., Ltd., China), and both the purity and concentration of these RNA samples were determined using a NanoDrop 2000 spectrophotometer (Thermo Scientific Co., Ltd., USA), by measuring their absorbance ratio at 260/280 nm and 260/230 nm. Reverse transcription was performed using the BioRT cDNA First Strand Synthesis Kit (TransGen Biotech Co., Ltd., China). Real-time Quantitative Polymerase Chain Reaction (qRT-PCR) was performed with at least three biological replicates using SYBR Green-based detection in triplicate in a 7500 Real-Time PCR System (Applied Biosystems, Inc., USA). The 16S rRNA gene was chosen as an internal control to normalize RNA amounts. The following primers were used: ilv2 (forward 5'-CGTCCAATTCCTCTTGCTTC-3', reverse 5'-ATGGCAATCCCTGTTCTACG-3'); $b d h 1$ (forward 5'-TTTGCTGAACAAGTCGTAGTC-3', reverse 5'-CCCAGTTTCTTGGCCATTTC-3'); 16S rRNA (forward 5'-TCACCAGGTCCAGACACAAT-3', reverse 5'-AGCAGACAAATCACTCCACC-3'). Diluted cDNA equivalent to 1 ng RNA starting material was used as the template for qRT-PCR amplification. The transcriptional levels of $i l v 2$ and $b d h 1$ were normalized to the transcriptional level of the 16S rRNA gene. The relative changes ( $x$-fold) at the transcriptional level in different samples were calculated (Ge et al. 2020). 
150 The $6 \mathrm{~mL}$ strain fermentation broth was centrifuged at $5000 \mathrm{rpm} / \mathrm{min}$ and $4{ }^{\circ} \mathrm{C}$ to collect the precipitate, 151 washed twice with potassium phosphate buffer (100 mM, pH 7.4), and resuspended in the buffer. The 152 cell supernatant after sonication is placed in an ice bath and used as a crude enzyme solution for 153 measuring enzyme activity. The BDH1 enzyme unit is defined as the amount ( $\mu$ mol) of a unit of BDH 154 activity per unit mass (mg) of total protein oxidized into $\mathrm{NAD}^{+}$in a unit of time (min). ILV2 enzyme 155 unit is defined as the amount ( $\mu \mathrm{mol})$ of a unit of ILV2 activity per unit mass (mg) of enzyme protein to 156 catalyze the synthesis of $\alpha$-acetolactate in a unit of time (min) (Zhang et al. 2016). All enzyme activities 157 are measured in triplicate.

\section{Metabolite detection}

Metabolites such as acetic acid and 2,3-BD were determined by HPLC. Shimadzu LC20A high-

160 performance liquid chromatography analysis system: RID-10A differential detector, LC-10ATvp pump and HPX-87H column (300×7.8 mm, Aminex HPX-87H Ion Exclusion column). The fermentation broth sample was diluted 100 times and centrifuged and the supernatant was collected. After filtering with a $0.45 \mu \mathrm{m}$ bacterial filter, the injection volume was $15 \mu \mathrm{L}, 0.005 \mathrm{~mol} / \mathrm{L}$ sulfuric acid was used as the mobile phase, the flow rate was $0.8 \mathrm{~mL} / \mathrm{min}$, and the column oven temperature was $65{ }^{\circ} \mathrm{C}$, fermentation metabolite analysis for $18 \mathrm{~min}$.

\section{Statistical analysis}

The data were statistically analyzed using Microsoft Office Excel 2016 (Microsoft, Redmond, WA) and SPSS 10.0 (SPSS Inc. Chicago, IL, USA) and are expressed the mean \pm SD. In our work, the SD data were obtained from three independent experiments and averaged. OriginPro 2021 (OriginLab, Northampton, MA) was used for chart analysis. $p<0.05$ (represented by *) was considered a significant difference, $p<0.01$ (represented by $* *$ ) was considered an extremely significant difference.

\section{Results}

\section{Defining the threshold concentration of $S$. cerevisiae W141}

175 The threshold concentration is defined as the culture condition that does not produce 2,3-BD when the 176 cell density of $S$. cerevisiae W141 is lower than the threshold. It can be observed from Table 2 that 
different inoculation amounts exert no obvious effect on the cell density, and the carbon source (glucose)

in the medium is the main factor which can affect the bacterial count. When the carbon source is not changed (control group), the cell density $\left(O D_{600 \mathrm{~nm}}\right.$ value) in the fermentation broth is the highest, the second is when the carbon source is $1 / 2$, and the cell density of $1 / 5$ is the lowest. In the meanwhile, the cup and dish method was employed to detect the relationship between the yield of 2,3-BD and cell density under 9 different culture conditions (Table 2). Under 1/5 carbon source culture conditions, the yield of 2,3-BD cannot be detected regardless of the inoculum amount of $5 \%, 2 \%$, or $0.5 \%$, and the $O D_{600 \mathrm{~nm}}$ values were respectively $9.683 \pm 0.732,9.613 \pm 0.611$ and $9.014 \pm 0.571$, all of which are less than 10 . Therefore, it can be proved that the yield of 2,3-BD within the certain range is directly proportional to the cell density of the fermentation broth. The production process of 2,3-BD is dependent on cell density, and the threshold concentration to be reached is $O D_{600 \mathrm{~nm}}$ is 10 (cell density is $4.4 \times 10^{8} \mathrm{CFU} / \mathrm{mL}$ ). In addition, it can also be determined that the threshold density culture condition is $1 / 5$ carbon source medium and the inoculation amount is $5 \%$. Therefore, this condition can be used to determine whether co-cultivation with other microorganisms can promote $S$. cerevisiae W141 in order to produce more 2,3BD.

\section{The effect of adding different concentrations of acetic acid on cell density and 2,3-BD}

Studies have found that the addition of acetic acid can induce the synthesis of 2,3-BD, indicating that 2,3-BD as a neutral metabolite, can offset excessive acidification levels (Syu 2001). Therefore, the addition of acetic acid can increase 2,3-BD production by inducing enzymes involved in the 2,3-BD pathway (Celińska and Grajek 2009). However, a large amount of acetic acid will increase the carbon flux in the metabolic pathway. As a result, a large amount of acetic acid will be harmful to cell growth. In other words, when the concentration of acetic acid is too high, it can inhibit microorganism growth (Sandoval et al. 2011). Relevant studies have proved that in the addition of 1-10 g/L of acetic acid, high concentration of acetic acid is usually used as an inhibitor of bacterial growth (Martin et al. 2007; GarciaAparicio et al. 2006). At the same time, the growth of Escherichia coli was inhibited when the concentration of acetic acid was $0.5 \mathrm{~g} / \mathrm{L}$ (Roe et al. 1998). In the present study, we chose to add $1 \mathrm{~g} / \mathrm{L}, 1.5 \mathrm{~g} / \mathrm{L}$ and $2 \mathrm{~g} / \mathrm{L}$ acetic acid to determine the changes in biomass and 2,3-BD yield in the fermentation process of S. cerevisiae W141 (Fig. 2). The results demonstrated that the $O D_{600 \mathrm{~nm}}$ value ended to first rise and then maintain stable, at the same time, with 
adding $1 \mathrm{~g} / \mathrm{L}$ and $1.5 \mathrm{~g} / \mathrm{L}$ acetic acid, the highest yields of 23 -BD reached respectively $2.93 \pm 0.02 \mathrm{~g} / \mathrm{L}$ $(84 \mathrm{~h})$ and $3.01 \pm 0.04 \mathrm{~g} / \mathrm{L}(84 \mathrm{~h})$, which were compared with the control group $(1.71 \pm 0.02 \mathrm{~g} / \mathrm{L})$. In addition, it was increased respectively by $71.4 \%$ and $76.0 \%(p<0.01)$. At the same time, the $O D_{600 \mathrm{~mm}}$ value has no obvious effect after adding $1 \mathrm{~g} / \mathrm{L}$ acetic acid, while the $O D_{600} \mathrm{~nm}$ value dropped to $14.46 \pm$ 0.93 (cell density is $6 \times 10^{8} \mathrm{CFU} / \mathrm{mL}$ ) after adding $1.5 \mathrm{~g} / \mathrm{L}$. After adding $2 \mathrm{~g} / \mathrm{L}$ acetic acid, the 2,3-BD yield decreased to $1.45 \pm 0.02 \mathrm{~g} / \mathrm{L}(84 \mathrm{~h})$, which was $17.9 \%$ lower than the control group $(p<0.01)$. Meanwhile, the $O D_{600 \mathrm{~nm}}$ value dropped to $13.62 \pm 0.48$. (cell density is $5.7 \times 10^{8} \mathrm{CFU} / \mathrm{mL}$ ). Consequently, the relationship between acetic acid and 2,3-BD during the fermentation of S. cerevisiae W141 has a certain coupling, that is, when acetic acid reaches a concentration of $1.5 \mathrm{~g} / \mathrm{L}$, it can effectively promote the production of 2,3-BD, and excessive addition of acetic acid will lead to a decrease in the production and cell density of 2,3-BD and inhibit its growth.

\section{The effect of acetic acid on microorganisms under co-culture conditions}

According to the results of the previous single-factor experiment, the fermentation conditions for cocultivation include the inoculation ratio is $4: 2$, the fermentation temperature is $30^{\circ} \mathrm{C}$, the rotation speed is $140 \mathrm{r} / \mathrm{min}$, and the inoculation time is $12 \mathrm{~h}$. Besides, the output of 2,3-BD reached its maximum at that time. We further carry out orthogonal optimization test for four factors, and each factor has three different levels of orthogonal experimental design (Table 1). In accordance with the production of 2,3-BD determined by each experimental design and the influence of these factors on the production of acetic acid, according to the $\mathrm{R}$ value (Table 3), the influence of four factors on the concentration of 2,3-BD decreases in order: (A) inoculation amount, (B) temperature, (C) rotation speed and (D) inoculation time. Based on the order of $\mathrm{K}$ value (Table 3), the best combination is $\mathrm{A}_{2} \mathrm{~B}_{2} \mathrm{C}_{3} \mathrm{D}_{1}$, corresponding to a fermentation temperature of $32{ }^{\circ} \mathrm{C}$, a rotation speed of $160 \mathrm{r} / \mathrm{min}$, an inoculation time of $0 \mathrm{~h}$, and an inoculation amount of S. cerevisiae W141 and A. pasteurianus HN 1.01 are 4\% and 2\% respectively. Under the optimal technological conditions, the average output of 2,3-BD in the three parallel experiments was $2.612 \pm 0.003 \mathrm{~g} / \mathrm{L}$.

Under optimal culture conditions, samples were taken from the culture medium in order to analyze changes in glucose concentration, biomass, ethanol, acetic acid, and 2,3-BD content. As shown in Fig. 3a, during the fermentation process, glucose was used as a carbon source and was quickly utilized by $S$. cerevisiae W141 in the first $24 \mathrm{~h}$. At the same time, with the maximum amount being $40.02 \pm 1.72 \mathrm{~g} / \mathrm{L}$ ( $24 \mathrm{~h}$ ), the content of ethanol increased significantly. Therefore, the first $24 \mathrm{~h}$ is the main synthesis period 

oxidation produces acetic acid (Mamlouk and Gullo 2013). The output of acetic acid reached a maximum of $2.437 \pm 0.056 \mathrm{~g} / \mathrm{L}$ at $24 \mathrm{~h}$, and then showed a slow decline. However, after $24 \mathrm{~h}$, the output of acetic acid decreased. At this time, the content of 2,3-BD increased significantly. Through comparing the changes in the content of acetic acid and 2,3-BD, it can be observed that the output of 2,3-BD is inversely proportional to the content of acetic acid. It reveals that S. cerevisiae W141 is using acetic acid to produce 2,3-BD. As shown in Fig. 3b, when the biomass of S. cerevisiae W141 increased, the growth of $A$. pasteurianus $\mathrm{HN} 1.01$ was inhibited, and the cell number decreased from $1.95 \times 10^{8} \mathrm{CFU} / \mathrm{mL}$ at $60 \mathrm{~h}$ to $1.41 \times 10^{8} \mathrm{CFU} / \mathrm{mL}$ at $48 \mathrm{~h}$. However, the co-culture conditions exert no significant effect on the cell number of S. cerevisiae W141. In other words, the process of converting ethanol to acetic acid was masked by the inhibition of the activity of A. pasteurianus HN 1.01. Therefore the cell number of $A$. pasteurianus $\mathrm{HN} 1.01$ decreased.

Comparison of the 2,3-BD yield changes under the optimal conditions of co-cultivation, yeast monoculture, and addition of $1.5 \mathrm{~g} / \mathrm{L}$ acetic acid, can be seen from the results of Fig. 4a. Under the optimal culture conditions, the maximum yield of 2,3-BD tested was $3.11 \pm 0.02 \mathrm{~g} / \mathrm{L}$ (72 h), which was $81.9 \%$ higher than the original strain $(p<0.01)$. Simultaneously, compared with adding $1.5 \mathrm{~g} / \mathrm{L}$ acetic acid, the yield increased by $3.3 \%(p<0.05)$. Additionally, it could also be found that under the optimal culture conditions, the acetic acid produced was higher than that of S. cerevisiae W141 monoculture and $1.5 \mathrm{~g} / \mathrm{L}$ acetic acid (Fig. 4b). Therefore, it can be proved that $S$. cerevisiae W141 will use the acetic acid produced by A. pasteurianus $\mathrm{HN} 1.01$ to promote the production of 2,3-BD. The decrease of acetic acid content will lead to the production of 2,3-BD decline, also further explaining that acetic acid can be used as a signal molecule under co-culture conditions to affect the content of 2,3-BD produced by S. cerevisiae W141.

\section{ILV2 and BDH1 enzyme activity detection and mRNA expression of related genes}

In order to further explore that acetic acid acting as a signal molecule can promote the activity of key enzymes and gene expression in the metabolic pathway of S. cerevisiae W141, we will detect the enzyme activity of acetolactate synthase (ILV2) and 2,3-BD dehydrogenase (BDH1) in the metabolic pathway under the optimal conditions of co-cultivation. S. cerevisiae W141 was used as a control to detect the changes in the key enzyme activity of 2,3-BD under the optimal conditions of co-cultivation and after 
conditions for co-cultivation, the enzyme activity of ILV2 first increases, decreases and then increases with the extension of the fermentation time. Finally, it stabilizes, and the maximum enzyme activity reaches $1.519 \pm 0.022 \mathrm{U} / \mathrm{mg}(24 \mathrm{~h})$. Compared with the control group $(0.774 \pm 0.022 \mathrm{U} / \mathrm{mg})$ and the 1.5 $\mathrm{g} / \mathrm{L}$ acetic acid group $(1.412 \pm 0.022 \mathrm{U} / \mathrm{mg})$, the increase was $96.3 \%$ and $7.6 \%$, respectively. It can be seen from Fig. 5b that the BDH1 enzyme activity under the three groups presented a trend of increasing and then decreasing. In addition, the enzyme activity under the optimal conditions of co-cultivation reached a maximum of $0.1634 \pm 0.0026 \mathrm{U} / \mathrm{mg}(60 \mathrm{~h})$, respectively comparison with the control group $(0.0976 \pm 0.0015 \mathrm{U} / \mathrm{mg})$ and the $1.5 \mathrm{~g} / \mathrm{L}$ acetic acid group $(0.1212 \pm 0.0032 \mathrm{U} / \mathrm{mg})$ increased by $67.4 \%$ and $34.8 \%$. This proves that under the optimal conditions of co-cultivation, the key enzyme activities of the 2,3-BD metabolic pathway of S. cerevisiae W141 have been significantly increase. Consequently, the output of 2,3-BD has been greatly improved.

This study used qRT-PCR technology to detect the expression of $i l v 2$ and $b d h 1$ gene. The CT value of each sample was analyzed by employing the relative quantitative $2^{-\Delta \Delta C T}$ method, and the relative expression of the ilv2 and $b d h 1$ genes was calculated (Fig. 6). According to the results, the relative expression levels of $i l v 2$ gene were higher than those in the control group after adding $1 \mathrm{~g} / \mathrm{L}$ and $1.5 \mathrm{~g} / \mathrm{L}$ acetic acid, which were 3.37 times and 5.56 times the gene expression levels respectively, and the relative expression level of ilv2 gene under optimal co-culture condition was 4.52 times that of control group. The relative expression of $i l v 2$ gene was 4.52 times that of the control group $(p<0.01)$. After adding 2 $\mathrm{g} / \mathrm{L}$ acetic acid, the relative expression of the $i l v 2$ gene was down-regulated, which was $20.5 \%$ lower than that of the control group $(p<0.01)$. At the same time, the relative expression of $b d h 1$ gene in S. cerevisiae W141 after the addition of $1 \mathrm{~g} / \mathrm{L}$ and $1.5 \mathrm{~g} / \mathrm{L}$ acetic acid was also higher than that of the control group, which was respectively 1.35 times and 1.12 times that of its gene expression. Under the optimal cocultured conditions, the relative expression of $b d h 1$ gene was 4.52 times that of the control group $(p<$ 0.01), while the relative expression of $b d h 1$ gene was down-regulated after adding $2 \mathrm{~g} / \mathrm{L}$ acetic acid, which was $85.2 \%$ lower than that of the control group $(p<0.01)$. It shows that there is QS between $S$. cerevisiae and A. pasteurianus HN1.01, and the acetic acid produced by fermentation of A. pasteurianus HN1.01 can be used as a signal molecule to up-regulate the expression of key enzyme genes in the 2,3BD synthesis pathway, and subsequently improve the activity of related enzymes to achieve the purpose of increasing 2,3-BD. 
2,3-BD acting as a platform chemical was extensively used in various fields such as food and medicine

299 (Kim et al. 2019). In general, numerous bacteria had an endogenous metabolic pathway to produce 2,3-

300 BD, including S. cerevisiae (Kim et al. 2016), Enterobacter cloacae (Li et al. 2015), Klebsiella

301 (Rathnasingh et al. 2016; Ji et al. 2008) and Bacillus licheniformis (Qiu et al. 2016) and these bacteria

302 have been proved to produce 2,3-BD. Lee et al. (2016) found that when E. aerogenes are cultured, the

303 addition of external acetic acid could increase the production of 2,3-BD by $32.4 \%$. Yu et al. (1982)

304 discovered that the addition of less than $1 \mathrm{~g} / \mathrm{L}$ of acetic acid can increase the production of 2,3-BD by 2-

3053 times when $K$. pneumoniae is a substrate containing nutrients such as glucose and xylose. For $S$.

306 cerevisiae, excessive acetic acid will promote the production of acetolactate and decrease the intracellular

$307 \mathrm{pH}$. In order to avoid excessive acetic acid at this time, pyruvate tilts to the 2,3-BD pathway, and uses

308 the means of converting acidic products to avoid the phenomenon of excessive acid in the cell. In other

309 words, it is beneficial to the production of 2,3-BD under acidic conditions, consequently indicating that

310 acetic acid exerts an indispensable role in the entire production process of 2,3-BD. At the same time,

311 studies have been shown that acetic acid can be used as a signal molecule to affect cell membranes,

312 bacteriocins and QS (Elmassry et al. 2020; Ge et al. 2019). Therefore, it can also be believed that in the

313 S. cerevisiae quorum sensing system, acetic acid has the potential as a signal molecule.

314 Some studies have found that the production process of 2,3-BD is affected by a lot of factors, such as

315 ventilation, $\mathrm{pH}$ and cell density (Tong et al. 2015; Kalia 2013). Based on our obtained data, the yield of

$3162,3-\mathrm{BD}$ is affected by the cell density of S. cerevisiae. When the cell density of the fermentation broth is

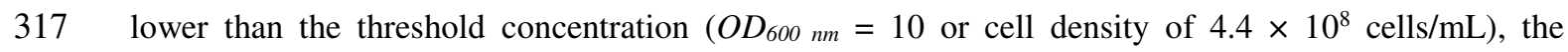

318 production of 2,3-BD cannot be detected. Under the same conditions, when the cell density is higher than

319 the threshold concentration, the production of 2,3-BD is found. Therefore, high cell density facilitates

320 the production of high levels of 2,3-BD. However, it has been found that the signal molecules produced

321 by some strains have a certain relationship with cell density. As a result, it shows that the production of

322 2,3-BD is affected and controlled by the cell density of S. cerevisiae W141 flora without being influenced

323 by other substances. At the same time, in the metabolic process of 2,3-BD production by S. cerevisiae,

324 acetic acid promotes the expression of the three key genes ( $b u d A$, budB and $b u d C$ ) from pyruvate to 2,3-

325 BD. Acetic acid can regulate the balance of acetoin to 2,3-BD and induce the enhancement of BDH

326 enzyme activity. Additionally, it has been confirmed that under the premise of reasonable allocation of 
carbon sources, the production of 2,3-BD can be increased by adding appropriate acetic acid (Xu et al. 2014). Moreover, the present study explored the effect of acetic acid as a signal molecule on the production of 2,3-BD by adding different concentrations of acetic acid from an external source. The results showed that when $1.5 \mathrm{~g} / \mathrm{L}$ acetic acid was added to the fermentation broth of S. cerevisiae W141, the yield of 2,3-BD reached $3.01 \pm 0.04 \mathrm{~g} / \mathrm{L}$ ( $84 \mathrm{~h}$ ), which was an increase of $76.02 \%$ compared with the control group. At this time, the strain $O D_{600} n m$ value has fallen. It shows that adding a certain concentration of acetic acid from external sources can promote the production of 2,3-BD. At the same time, Lee et al. (2016) also reached a similar conclusion. When they explored the effect of acetic acid on the production of 2,3-BD by bacteria, they found that when a certain concentration of acetic acid was added to E. aerogenes, the $\mathrm{pH}$ of the medium was adjusted to 6.5 and the yield of 2,3-BD was increased, indicating that the addition of acetic acid exerted a certain stimulating effect on 2,3-BD.

Through conducting further co-cultivation experiments, we found that 2,3-BD production will be affected by the growth and metabolism of A. pasteurianus HN1.01 to produce acetic acid. Under the optimal co-cultivation conditions, the yield of 2,3-BD was higher than the original strain and the $1.5 \mathrm{~g} / \mathrm{L}$ acetic acid group. There are reports showing that the metabolism of 2,3-BD is regulated by QS system (Jin et al. 2019). Suh et al. (2000) obtained similar results when exploring the mixed culture of Monascus J101 and S. cerevisiae, that is, the pigment yield of the co-cultivation was 30-40 times higher than that of Monascus alone. In the meanwhile, during the co-cultivation of S. cerevisiae and A. pasteurianus, Wang et al. (2013) found that the ethanol produced by S. cerevisiae directly as fermentation with carbon sources can achieve the purpose of saving costs, consequently shortening fermentation time and increasing yield. This result is consistent with the results of the present study. In addition, this study also found that under the optimal conditions of co-cultivation, the expression levels of $i l v 2$ and $b d h 1$ genes were significantly up-regulated, and were higher than that of the acetic acid group. This result is consistent with the results of Lou et al. (2016) Therefore, under co-cultivation conditions, the acetic acid produced by fermentation of A. pasteurianus HN1.01 can be used as a signal molecule to successfully increase the relative expression of the key enzyme genes $i l v 2$ and $b d h 1$ in the 2,3-BD metabolic pathway, and simultaneously lead to ILV2 and BDH1 activity is also significantly increased to achieve the purpose of increasing 2,3-BD.

\section{Acknowledgements}




\section{Compliance with ethical standards}

359 Conflict of interest: The authors declare that there are no conflicts of interest.

360 Ethical statements: This article does not contain any studies with human participants or animals performed by any of the authors.

\section{References}

Anane E, López C DC, Neubauer P, Cruz Bournazou MN (2017) Modelling overflow metabolism in Escherichia coli by acetate cycling. Biochem Eng J 125:23-30

Arena MP, Capozzi V, Spano G, Fiocco D (2017) The potential of lactic acid bacteria to colonize biotic and abiotic surfaces and the investigation of their interactions and mechanisms. Appl Microbiol Biotechnol 101:2641-2657

Camilli A, Bassler BL (2006) Bacterial small-molecule signaling pathways. Science 311:1113-1116

Celińska E, Grajek W (2009) Biotechnological production of 2,3-butanediol-Current state and prospects. Biotechnol Adv 27:715-725

Cho JH, Rathnasingh C, Song H, Chung BW, Lee HJ, Seung D (2012) Fermentation and evaluation of Klebsiella pneumoniae and K. oxytoca on the production of 2,3-butanediol. Bioprocess Biosyst Eng $35: 1081-1088$

Elmassry MM, Farag MA, Preissner R, Gohlke BO, Piechulla B, Lemfack MC (2020) Sixty-one volatiles have phylogenetic signals across bacterial domain and fungal kingdom. Front Microbiol 11:557253

Gao J, Jiang RF, Cao C, Ni H, Zhang L, Deng LN, Xu H, Jiang RY (2019) Effects of amino acids on the fermentation of inulin or glucose to produce $R, R$-2,3-butanediol using Paenibacillus polymyxa ZJ9. Lett Appl Microbiol 69:424-430

Garcia-Aparicio MP, Ballesteros I, Gonzalez A, Oliva JM, Ballesteros M, Negro MJ (2006) Effect of inhibitors released during steam-explosion pretreatment of barley straw on enzymatic hydrolysis. Appl Biochem Biotechnol 129:278-288

Ge JP, Kang J, Ping WX (2019) Effect of acetic acid on bacteriocin production by gram-positive bacteria. J Microbiol Biotechnol 29:1341-1348

Ge JP, Wang JW, Ye GB, Sun SS, Guo R, Song G, Ping WX (2020) Disruption of the lactate 

dehydrogenase and acetate kinase genes in Klebsiella pneumoniae HD79 to enhance 2,3-butanediol production, and related transcriptomics analysis. Biotechnol Lett 42:537-549

Guo XW, Wang YZ, Guo J, Wang Q, Zhang Y, Chen YF, Zhang CY, Xiao DG (2017) Efficient production of 2,3-butanediol from cheese whey powder (CWP) solution by Klebsiella pneumoniae through integrating pulsed fed-batch fermentation with a two-stage pH control strategy. Fuel 203:69-477

Ji XJ, Huang H, Li S, Du J, Lian M (2008) Enhanced 2,3-butanediol production by altering the mixed acid fermentation pathway in Klebsiella oxytoca. Biotechnol Lett 30:731-734

Jia FF, Zheng HQ, Sun SR, Pang XH, Liang Y, Shang JC, Zhu ZT, Meng XC (2018) Role of luxS in stress tolerance and adhesion ability in Lactobacillus plantarum KLDS1.0391. Biomed Res Int 2018:1-10

Jin WS, Lin H, Gao HF, Guo ZW, Li JH, Xu QM, Sun SJ, Hu KH, Lee JK, Zhang LY (2019) N-Acylhomoserine lactone quorum sensing switch from acidogenesis to solventogenesis during the fermentation process in Serratia marcescens MG1. J Microbiol Biotechnol 29:596-606

Kalia VC (2013) Quorum sensing inhibitors: an overview. Biotechnol Adv 31:224-245

Kareb O, Aïder M (2019) Quorum sensing circuits in the communicating mechanisms of bacteria and its implication in the biosynthesis of bacteriocins by lactic acid bacteria: a review. Probiotics Antimicrob Proteins 12:5-17

Kim JW, Kim J, Seo SO, Kim KH, Jin YS, Seo JH (2016) Enhanced production of 2,3-butanediol by engineered Saccharomyces cerevisiae through fine-tuning of pyruvate decarboxylase and NADH oxidase activities. Biotechnol Biofuels 9:265

Kim JW, Lee YG, Kim SJ, Jin YS, Seo JH (2019) Deletion of glycerol-3-phosphate dehydrogenase genes improved 2,3-butanediol production by reducing glycerol production in pyruvate decarboxylasedeficient Saccharomyces cerevisiae. J Biotechnol 304:31-37

Kim JW, Seo SO, Zhang GC, Jin YS, Seo JH (2015) Expression of Lactococcus lactis NADH oxidase increases 2,3-butanediol production in Pdc-deficient Saccharomyces cerevisiae. Bioresour Technol $191: 512-519$

Lee SJ, Thapa LP, Lee JH, Choi HS, Kim SB, Park C, Kim SW (2016) Stimulation of 2,3-butanediol production by upregulation of als $R$ gene transcription level with acetate addition in Enterobacter aerogenes ATCC 29007. Process Biochem 51:1904-1910

Li LX, Li K, Wang Y, Chen C, Xu YQ, Zhang LJ, Han BB, Gao C, Tao F, Ma CQ, Xu P (2015) Metabolic 
engineering of Enterobacter cloacae for high-yield production of enantiopure (2R,3R)-2,3butanediol from lignocellulose-derived sugars. Metab Eng 28:19-27

Luo HZ, Ge LB, Zhang JS, Ding J, Chen R, Shi ZP (2016) Enhancing acetone biosynthesis and acetone-

performance

by

co-culturing

Clostridium acetobutylicum/Saccharomyces cerevisiae integrated with exogenous acetate addition. Bioresour Technol 200:111-120

Suh JH, Shin CS (2000) Physiological analysis on novel coculture of Monascus sp. J101 with screening study. Int J Food Microbiol 144:270-279

Priya A, Dureja P, Talukar P, Rathi R, Lal B, Sarma PM (2016) Microbial production of 2,3-butanediol through a two-stage pH and agitation strategy in 1501 bioreactor. Biochem Eng J 105:159-167

Qiu YM, Zhang JY, Li L, Wen ZY, Nomura CT, Wu SL, Chen SW (2016) Engineering Bacillus licheniformis for the production of meso-2,3-butanediol. Biotechnol Biofuels 9:117

Rathnasingh C, Park JM, Kim DK, Song H, Chang YK (2016) Metabolic engineering of Klebsiella pneumoniae and in silico investigation for enhanced 2,3-butanediol production. Biotechnol Lett $38: 975-982$

Roe AJ, Mclaggan D, Davidson I, O'byrne C, Booth IR (1998) Perturbation of anion balance during inhibition of growth of Escherichia coli by weak acids. J Bacteriol 180:767-772

Sandoval NR, Mills TY, Zhang M, Gill RT (2011) Elucidating acetate tolerance in E. coli using a genomewide approach. Metab Eng 13:214-224

Studer SV, Mandel MJ, Ruby EG (2008) AinS quorum sensing regulates the Vibrio fischeri acetate switch. J Bacteriol 190:5915-5923

Saccharomyces cerevisiae. FEMS Microbiol Lett 190:241-245

Sun SJ, Zhang HY, Lu SY, Lai CF, Liu HJ, Zhu H (2016) The metabolic flux regulation of Klebsiella 
Syu MJ (2001) Biological production of 2,3-butanediol. Appl Microbiol Biotechnol 55:10-18

Tong YJ, Ji XJ, Shen MQ, Liu LG, Nie ZK, Huang H (2015) Constructing a synthetic constitutive metabolic pathway in Escherichia coli for $(R, R)$-2,3-butanediol production. Appl Microbiol Biotechnol 100:637-647

Turner TL, Kim H, Kong II, Liu JJ, Zhang GC, Jin YS (2016) Engineering and evolution of Saccharomyces cerevisiae to produce biofuels and chemicals. Adv Biochem Eng Biotechnol $162: 175-215$

Wang Z, Yan M, Chen X, Li DS, Qin L, Li ZJ, Yao J, Liang XL (2013) Mixed culture of Saccharomyces cerevisiae and Acetobacter pasteurianus for acetic acid production. Biochem Eng J 79:41-45

Xu YQ, Chu HP, Gao C, Tao F, Zhou ZK, Li K, Li LX, Ma CQ, Xu P (2014) Systematic metabolic

Yu EKC, Saddler JN (1982) Enhanced production of 2,3-butanediol by Klebsiella pneumoniae grown on high sugar concentrations in the presence of acetic Acid. Appl Environ Microbiol 44:777-784

Zhang LY, Guo ZW, Chen JB, Xu QM, Lin H, Hu KH, Guan X, Shen YL (2016) Mechanism of 2,3butanediol stereoisomers formation in a newly isolated Serratia sp. T241. Sci Rep 6:19257 
468 Table 1 Factors and their levels of orthogonal experiment $\mathrm{L}_{9}\left(3^{4}\right)$

\begin{tabular}{lccc}
\hline \multicolumn{1}{c}{ Constituent } & Level 1 & Level 2 & Level 3 \\
\hline A: inoculation amount $(\%, \mathrm{v} / \mathrm{v})$ & $3: 3$ & $4: 2$ & $2: 4$ \\
B: fermentation temperature $\left({ }^{\circ} \mathrm{C}\right)$ & 30 & 32 & 34 \\
C: rotate speed $(\mathrm{r} / \mathrm{min})$ & 120 & 140 & 160 \\
D: inoculation time $(\mathrm{h})$ & 0 & 12 & 24 \\
\hline
\end{tabular}

469 
470 Table 2 The yield of 2,3-BD and cell density of S. cerevisiae W141 under 9 different culture conditions

\begin{tabular}{ccccc}
\hline Groups & \multicolumn{2}{c}{ Culture condition } & Cell density $\left(O D_{600 \mathrm{~nm}}\right)$ & 2,3 -BD yield $(\mathrm{g} / \mathrm{L})$ \\
\hline 1 & $100 \%$ carbon source, & $5 \%$ & $15.073 \pm 0.627$ & $1.71 \pm 0.01$ \\
2 & $50 \%$ carbon source, & $5 \%$ & $10.664 \pm 0.823$ & $0.40 \pm 0.02$ \\
3 & 20\% carbon source, & $5 \%$ & $9.683 \pm 0.732$ & 0 \\
4 & $100 \%$ carbon source, & $2 \%$ & $14.394 \pm 0.599$ & $1.37 \pm 0.03$ \\
5 & $50 \%$ carbon source, & $2 \%$ & $10.553 \pm 0.487$ & $0.56 \pm 0.03$ \\
6 & $20 \%$ carbon source, & $2 \%$ & $9.613 \pm 0.611$ & 0 \\
7 & $100 \%$ carbon source, & $0.5 \%$ & $13.803 \pm 0.806$ & $0.81 \pm 0.02$ \\
8 & $50 \%$ carbon source, & $0.5 \%$ & $10.494 \pm 0.773$ & $0.29 \pm 0.01$ \\
9 & 20\% carbon source, & $0.5 \%$ & $9.014 \pm 0.571$ & 0 \\
\hline
\end{tabular}

471 
Table 3 Experimental design and results of the orthogonal experiment $\mathrm{L}_{9}\left(3^{4}\right)$

\begin{tabular}{cccccc}
\hline Run & $\mathrm{A}^{\mathrm{a}}$ & $\mathrm{B}$ & $\mathrm{C}$ & $\mathrm{D}$ & 2,3 -BD yield (g/L) \\
\hline 1 & 1 & 1 & 1 & 1 & $0.372 \pm 0.002$ \\
2 & 1 & 2 & 2 & 2 & $0.515 \pm 0.001$ \\
3 & 1 & 3 & 3 & 3 & $0.577 \pm 0.001$ \\
4 & 2 & 1 & 2 & 3 & $1.787 \pm 0.003$ \\
5 & 2 & 2 & 3 & 1 & $2.612 \pm 0.003$ \\
6 & 2 & 3 & 1 & 2 & $1.201 \pm 0.002$ \\
7 & 3 & 1 & 3 & 2 & $1.133 \pm 0.002$ \\
8 & 3 & 2 & 1 & 3 & $1.267 \pm 0.002$ \\
9 & 3 & 3 & 2 & 1 & $1.058 \pm 0.001$ \\
$\mathrm{~K}_{1}$ & $1.464 \pm 0.002$ & $3.292 \pm 0.001$ & $2.84 \pm 0.003$ & $4.042 \pm 0.001$ & \\
$\mathrm{~K}_{2}$ & $5.600 \pm 0.001$ & $4.394 \pm 0.002$ & $3.360 \pm 0.003$ & $2.849 \pm 0.004$ & \\
$\mathrm{~K}_{3}$ & $3.458 \pm 0.004$ & $2.836 \pm 0.005$ & $4.322 \pm 0.001$ & $3.631 \pm 0.002$ & \\
$\mathrm{R}$ & 2.068 & 0.779 & 0.741 & 0.5965 & \\
Optimal level & 2 & 2 & 3 & 1 & \\
\hline
\end{tabular}

473 a The symbols were the same as those in Table 1

474 
476 Fig. 1 The interaction between A. pasteurianus HN 1.01 and S. cerevisiae W141 in co-culture system.

477 The red area represents the acetic acid metabolism system from A. pasteurianus HN 1.01 and the blue 478 area represents the 2,3-BD metabolic system from $S$. cerevisiae W141

480 Fig. 2 The effects of adding different concentrations of acetic acid on the production of 2,3-BD and cell 481 density $\left(O D_{600} \mathrm{~nm}\right.$ value). The symbols indicate the different concentrations of acetic acid. $1 \mathrm{~g} / \mathrm{L}, 1.5 \mathrm{~g} / \mathrm{L}$ and $2 \mathrm{~g} / \mathrm{L}$ signify respectively the concentration of acetic acid under different treatment conditions. The bar chart shows the yield of 2,3-BD during the fermentation of $S$. cerevisiae W141, corresponding to the left Y-axis; The point plot shows the change of cell concentration $\left(O D_{600} \mathrm{~nm}\right.$ value) of $S$. cerevisiae W141, corresponding to the right $\mathrm{Y}$-axis. ) and (- - ) represent isolated culture of $S$. cerevisiae W141; $\square$ ) and (- $\square-\cdot)$ represent the addition of $1 \mathrm{~g} / \mathrm{L}$ acetic acid during the fermentation of $S$. cerevisiae W141; $(\square)$ and (๑-) denote the addition of $1.5 \mathrm{~g} / \mathrm{L}$ acetic acid during the fermentation of $S$. cerevisiae W141; $(\mathrm{ZA})$ and $(\cdot-\cdot)$ represents the addition of $2 \mathrm{~g} / \mathrm{L}$ acetic acid during the fermentation of $S$. cerevisiae W141

Fig. 3 The change of metabolites and cell density $\left(O D_{600 n m}\right.$ value) of $S$. cerevisiae W141 and $A$. pasteurianus HN 1.01 under optimal co-cultivation conditions. (a) The change of the yields glucose, ethanol, acetic acid and 2,3-BD under optimal co-culture conditions. The black square $(-\square)$, the black circle $(-\bullet-)$, the open square $(-\square \cdot \cdot)$ and the open circle $(\cdot \bullet \cdot \cdot)$ indicate respectively glucose, ethanol, acetic acid and 2,3-BD. (b) The change of cell density (OD $600 \mathrm{~nm}$ value) of $S$. cerevisiae W141 and $A$. pasteurianus HN 1.01 under the conditions of individual culture and optimal co-culture, respectively. The black square (--) represents the cell density in co-culture of S. cerevisiae W141. The black circle represent the cell density of $A$. pasteurianus HN 1.01 when being solely cultured

Fig. 4 When S. cerevisiae W141 and A. pasteurianus HN 1.01 were optimally co-cultured, the original strain S. cerevisiae W141 was solely cultured and S. cerevisiae W141 was added with $1.5 \mathrm{~g} / \mathrm{L}$ acetic acid in the production of 2,3-BD and acetic acid. (a) Metabolism of 2,3-BD under three treatment conditions; 
506 W141 and A. pasteurianus HN 1.01 were co-cultured under optimal conditions; $(\square)$ and $(\cdot-\bullet \cdot \cdot)$ stand for the original strain $S$. cerevisiae W141 was solely cultured; ( $\mathbb{A}$ ) and (ㄷ) represent that $S$. cerevisiae W141 was added with $1.5 \mathrm{~g} / \mathrm{L}$ acetic acid. Significance levels are presented as follows: $* p<$ $0.05, * * p<0.01$

Fig. 5 The enzyme activity of ILV2 and BDH1 of S. cerevisiae W141 and A. pasteurianus HN 1.01 were optimally co-cultured, the original strain S. cerevisiae W141 was solely cultured and S. cerevisiae W141 was added with $1.5 \mathrm{~g} / \mathrm{L}$ acetic acid. (a) The change of enzyme activity of ILV2 under three treatment conditions; (b) The change of enzyme activity of BDH1 under three treatment conditions. The red area $(\square)$ represents S. cerevisiae W141 and A. pasteurianus HN 1.01 were co-cultured under optimal conditions; the blue area ( $\square$ ) denotes the original strain $S$. cerevisiae W141 was solely cultured and the green area $(\square)$ represents $S$. cerevisiae W141 was added with $1.5 \mathrm{~g} / \mathrm{L}$ acetic acid

Fig. 6 The gene expression levels of S. cerevisiae W141 and A. pasteurianus HN 1.01 were optimally co-cultured, the original strain S. cerevisiae W141 was solely cultured and S. cerevisiae W141 was added with $1.5 \mathrm{~g} / \mathrm{L}$ acetic acid. ( $\square$ ) represents the ilv2 gene expression level at $24 \mathrm{~h}$; $b d h$ lgene expression level at $60 \mathrm{~h}$. Significance levels are as follows: ${ }^{*} p<0.05$ 
Figures

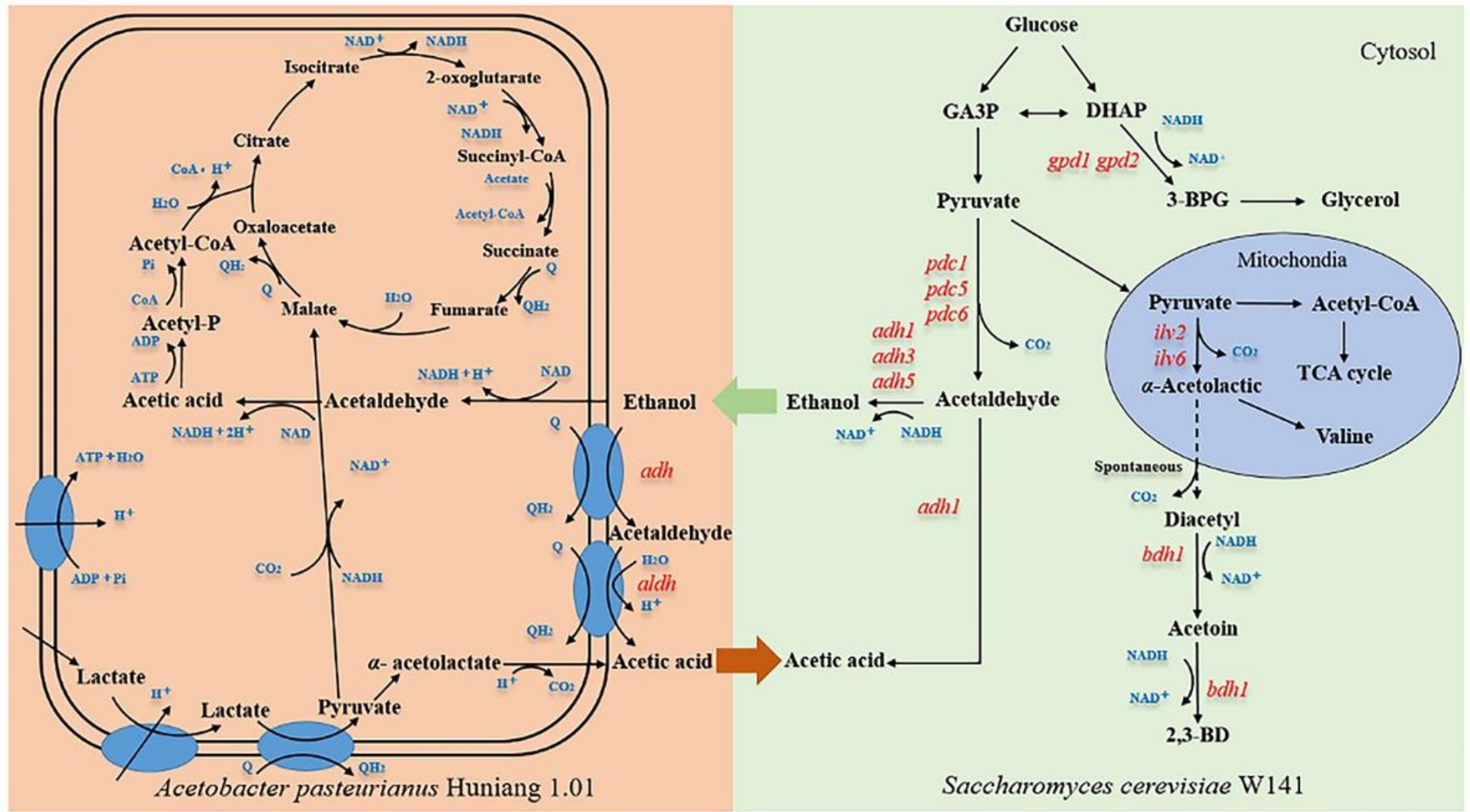

\section{Figure 1}

The interaction between A. pasteurianus HN 1.01 and S. cerevisiae W141 in co-culture system. The red area represents the acetic acid metabolism system from A. pasteurianus HN 1.01 and the blue area represents the 2,3-BD metabolic system from S. cerevisiae W141 


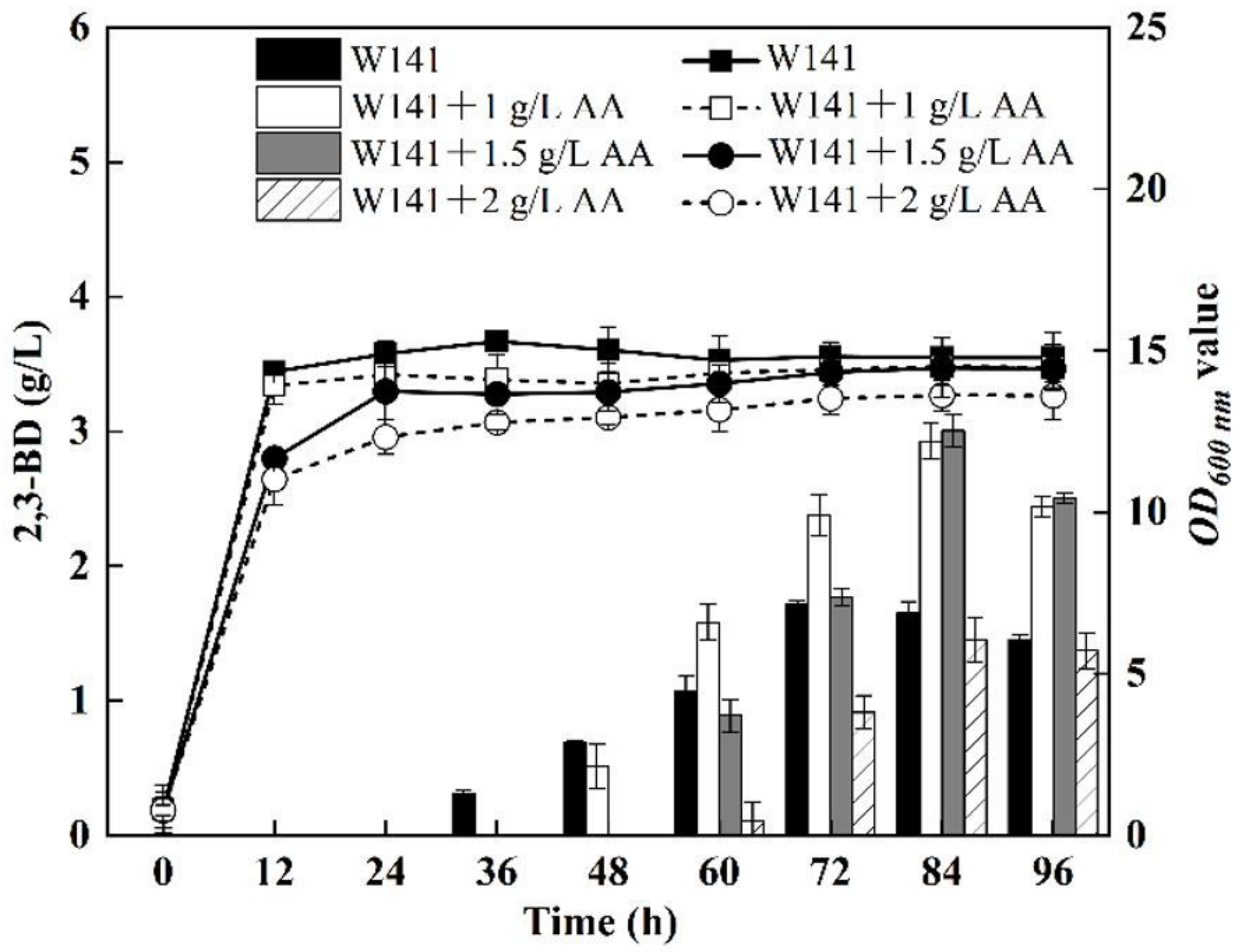

Figure 2

The effects of adding different concentrations of acetic acid on the production of 2,3-BD and cell density (OD600 nm value). The symbols indicate the different concentrations of acetic acid. $1 \mathrm{~g} / \mathrm{L}, 1.5 \mathrm{~g} / \mathrm{L}$ and 2 $\mathrm{g} / \mathrm{L}$ signify respectively the concentration of acetic acid under different treatment conditions. The bar chart shows the yield of 2,3-BD during the fermentation of S. cerevisiae W141, corresponding to the left Yaxis; The point plot shows the change of cell concentration (OD600 nm value) of S. cerevisiae W141,

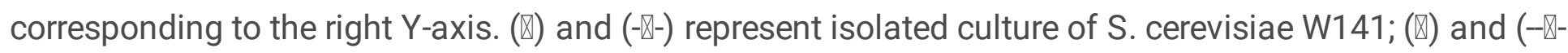
-) represent the addition of $1 \mathrm{~g} / \mathrm{L}$ acetic acid during the fermentation of S. cerevisiae W141; ( $($ ) and (-口-)

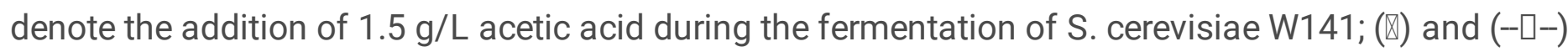
represents the addition of $2 \mathrm{~g} / \mathrm{L}$ acetic acid during the fermentation of S. cerevisiae W141 
a

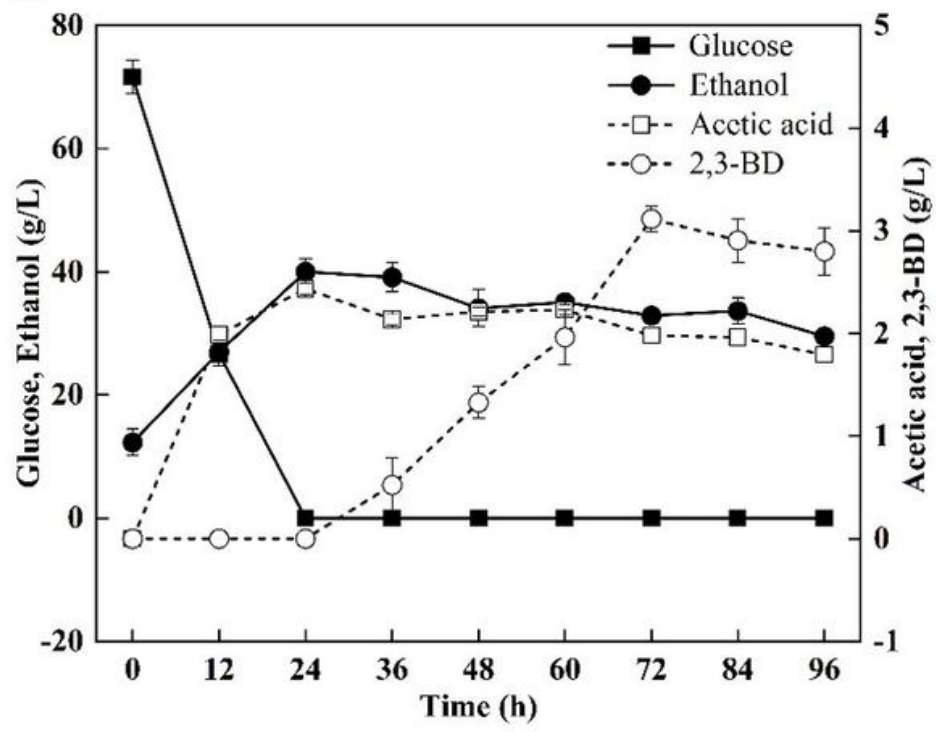

b

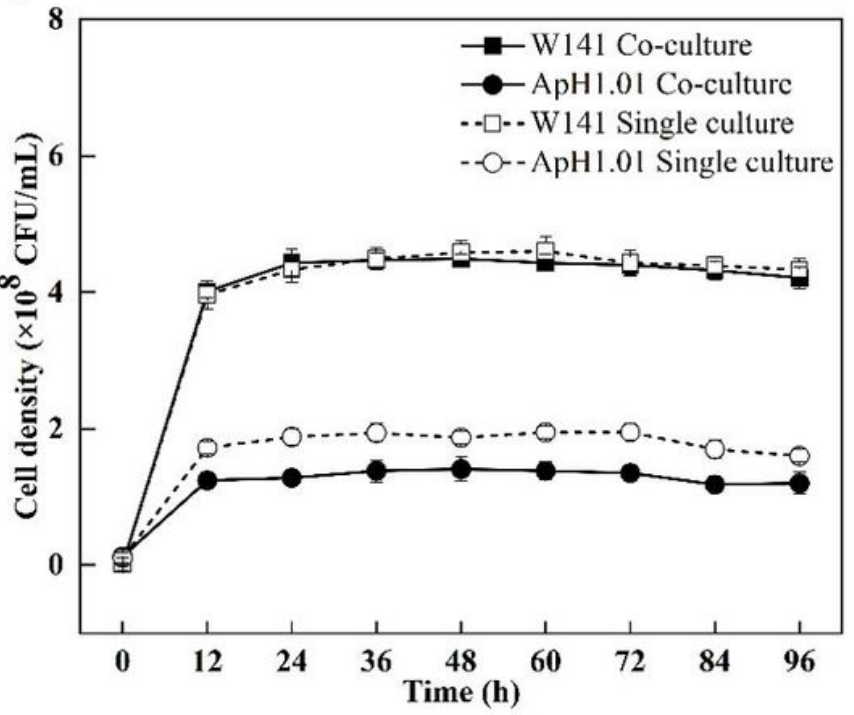

Figure 3

The change of metabolites and cell density (OD600nm value) of S. cerevisiae W141 and A. pasteurianus HN 1.01 under optimal co-cultivation conditions. (a) The change of the yields glucose, ethanol, acetic acid and 2,3-BD under optimal co-culture conditions. The black square (- - -), the black circle (-๑-) , the open square (-- - --) and the open circle (-- --) indicate respectively glucose, ethanol, acetic acid and 2,3-BD. (b) The change of cell density (OD600 nm value) of S. cerevisiae W141 and A. pasteurianus HN 1.01 under the conditions of individual culture and optimal co-culture, respectively. The black square (-囚-) represents the cell density in co-culture of S. cerevisiae W141. The black circle (- -) signifies the cell density in coculture of $A$. pasteurianus HN 1.01. The open square (--D--) represents the cell density of $S$. cerevisiae W141 when isolated culture and the open circle (---) represent the cell density of A. pasteurianus HN 1.01 when being solely cultured

a

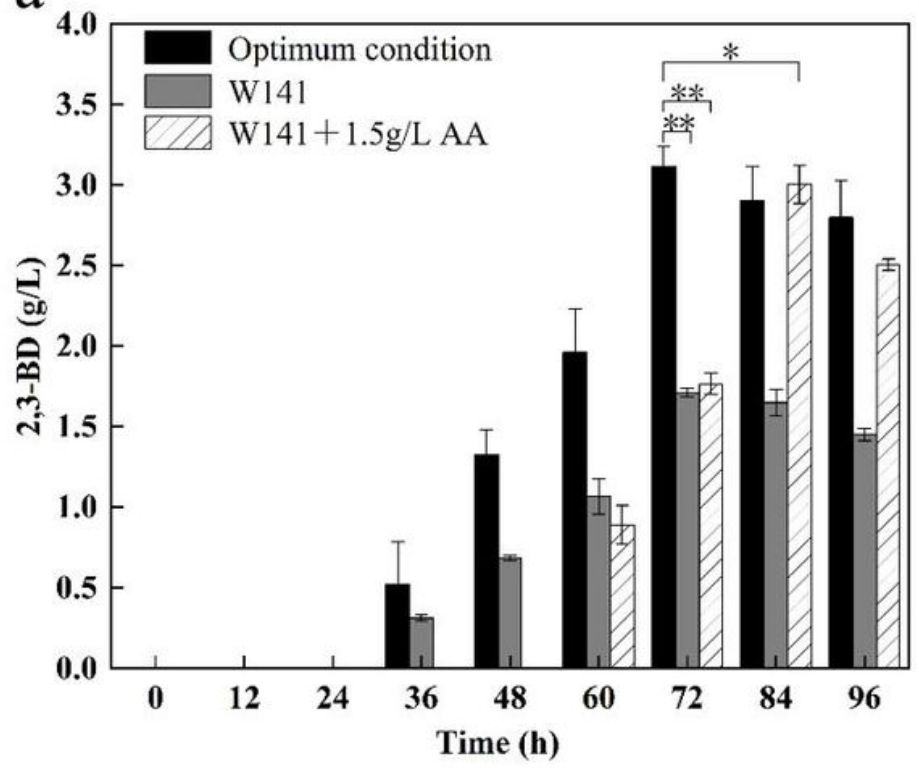

b

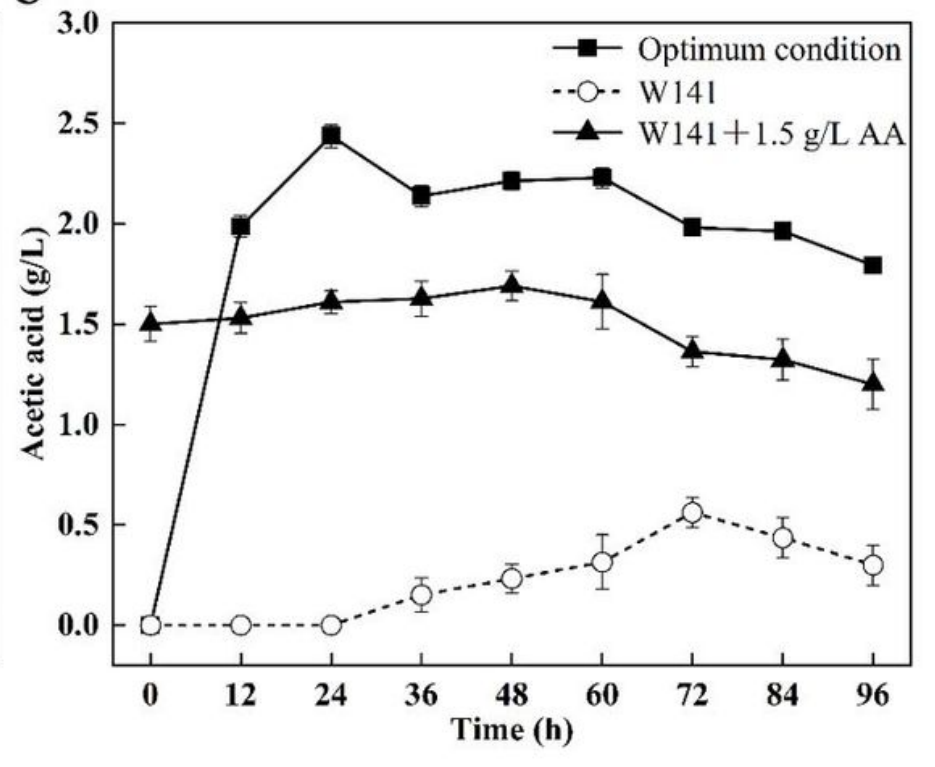




\section{Figure 4}

When S. cerevisiae W141 and A. pasteurianus HN 1.01 were optimally co-cultured, the original strain S. cerevisiae W141 was solely cultured and S. cerevisiae W141 was added with $1.5 \mathrm{~g} / \mathrm{L}$ acetic acid in the production of 2,3-BD and acetic acid. (a) Metabolism of 2,3-BD under three treatment conditions; (b) Metabolism of acetic acid under three treatment conditions. ( $(\mathbb{X})$ and (- $\mathbb{-}-)$ represent S. cerevisiae W141 and

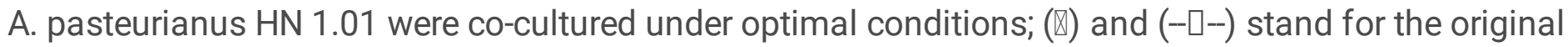

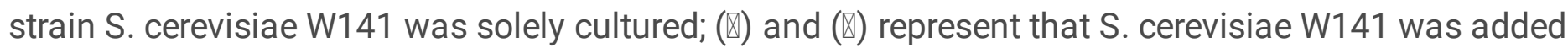
with $1.5 \mathrm{~g} / \mathrm{L}$ acetic acid. Significance levels are presented as follows: ${ }^{*} p<0.05,{ }^{*} \mathrm{p}<0.01$

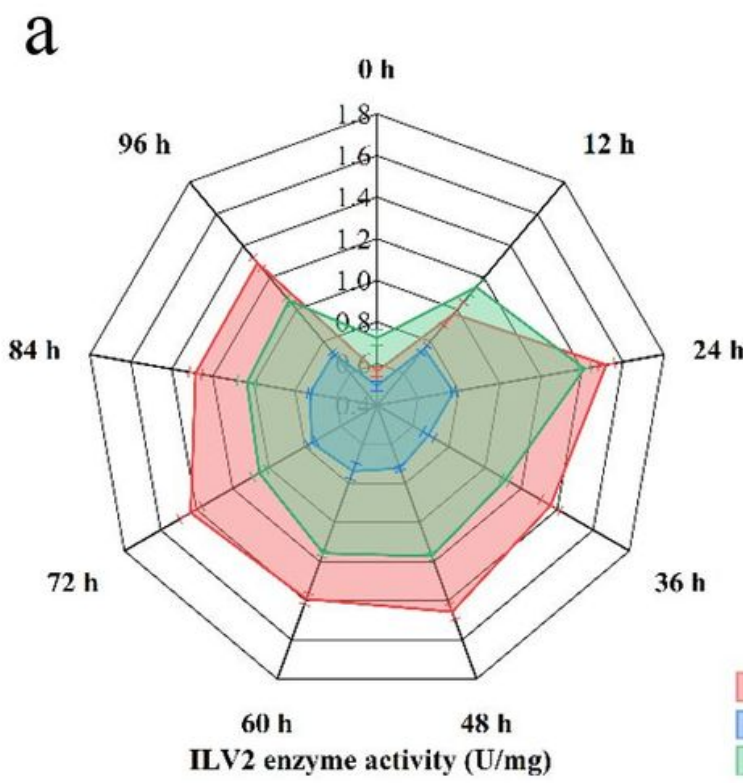

Optimum condition W141

$\mathrm{W} 141+1.5 \mathrm{~g} / \mathrm{L} \mathrm{AA}$

b

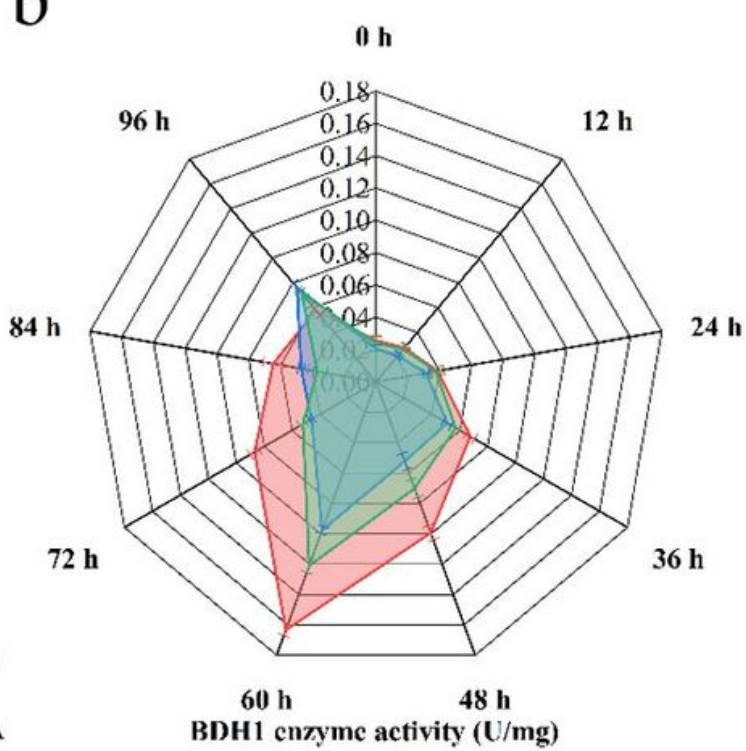

\section{Figure 5}

The enzyme activity of ILV2 and BDH1 of S. cerevisiae W141 and A. pasteurianus HN 1.01 were optimally co-cultured, the original strain S. cerevisiae W141 was solely cultured and S. cerevisiae W141 was added with $1.5 \mathrm{~g} / \mathrm{L}$ acetic acid. (a) The change of enzyme activity of ILV2 under three treatment conditions; (b) The change of enzyme activity of $\mathrm{BDH} 1$ under three treatment conditions. The red area (『) represents S. cerevisiae W141 and A. pasteurianus HN 1.01 were co-cultured under optimal conditions; the blue area (『) denotes the original strain S. cerevisiae W141 was solely cultured and the green area (邓) represents S. cerevisiae W141 was added with $1.5 \mathrm{~g} / \mathrm{L}$ acetic acid 


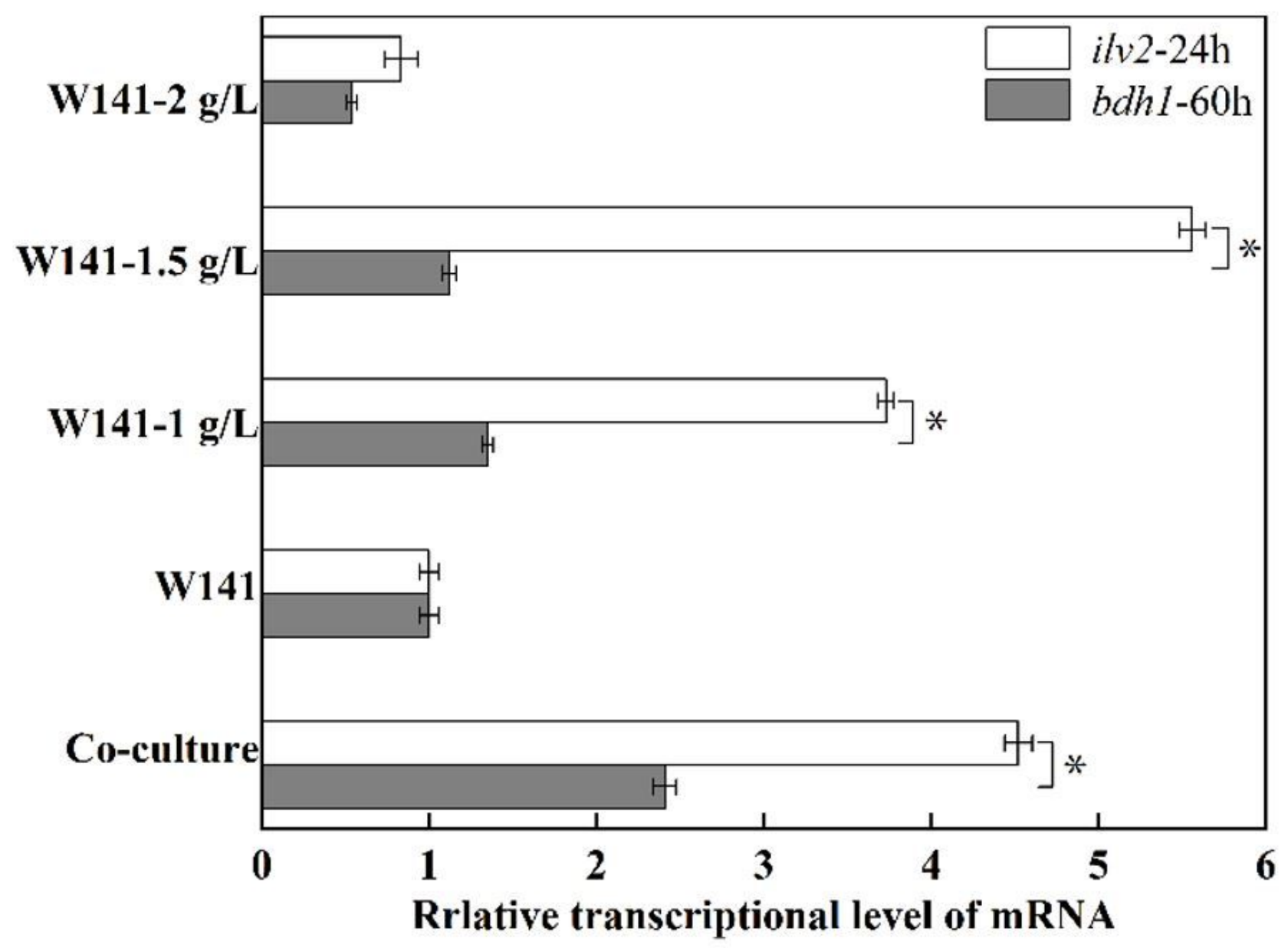

Figure 6

The gene expression levels of S. cerevisiae W141 and A. pasteurianus HN 1.01 were optimally cocultured, the original strain S. cerevisiae W141 was solely cultured and S. cerevisiae W141 was added

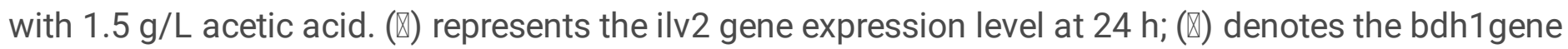
expression level at $60 \mathrm{~h}$. Significance levels are as follows: * $\mathrm{p}<0.05$ 